\title{
Does early detection of otitis media with effusion prevent delayed language development?
}

\author{
C C Butler, H MacMillan
}

\begin{abstract}
Objective-To consider whether earlier detection of otitis media with effusion (OME) in asymptomatic children in the first 4 years of life prevents delayed language development.

Methods-MEDLINE and other databases were searched and relevant references from articles reviewed. Critical appraisal and consensus development were in accordance with the methods of the Canadian Task Force on Preventive Health Care.

Results-No randomised controlled trials assessing the overall screening for OME and early intervention to prevent delay in acquiring language were identified, although one trial evaluated treatment in a screened population and found no benefit. The "analytic pathway" approach was therefore used, where evidence is evaluated for individual steps in a screening process. The evidence supporting the use of tools for early detection such as tympanometry, microtympanometry, acoustic reflectometry, and pneumatic otoscopy in the first 4 years of life is unclear. Some treatments (mucolytics, antibiotics, steroids) resulted in the short term resolution of effusions as measured by tympanometry. Ventilation tubes resolved effusions and improved hearing. Ventilation tubes in children with hearing loss associated with OME benefited children in the short term, but after 18 months there was no difference in comparison with those assigned to watchful waiting. Most prospective cohort studies that evaluated the association between OME and language development lacked adequate measurement of exposure or outcome, or suffered
\end{abstract}

Accepted 15 March 200

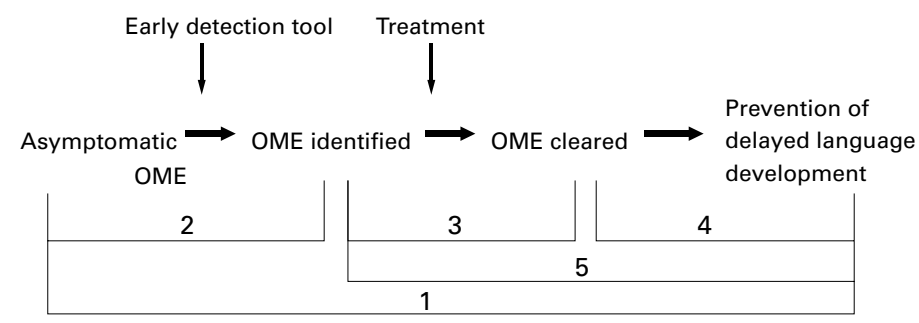

1. Does screening the general population of children in the first four years of life for OME prevent delayed language development?

2. Is there a suitable tool for early detection?

3. Is treatment effective in clearing OME?

4. Does treating OME improve language related outcomes?

5. Is OME associated with delayed language development?

Figure 1 Analytic pathway for the early detection of otitis media with effusion (OME) in the first 4 years of life to prevent delayed language development. from attrition bias. Findings with regard to the association were inconsistent. Conclusions-There is insufficient evidence to support attempts at early detection of OME in the first 4 years of life in the asymptomatic child to prevent delayed language development. (Arch Dis Child 2001;85:96-103)

Keywords: otitis media with effusion; language development disorders; speech disorders; child development

Otitis media with effusion (OME) is common, with a prevalence of about $20 \%$ at age 2 years. ${ }^{12}$ It is often asymptomatic. Some studies have found an association between OME and delayed language development, ${ }^{3}$ and this finding has led to the implementation of programmes for earlier detection of OME, although the evidence supporting attempts at earlier detection has been questioned. ${ }^{4}$ Clinicians conducting periodic health examinations or child health surveillance may question whether attempts at earlier diagnosis of $\mathrm{OME}$ should be included as a routine part of these examinations. Using the methods of the Canadian Task Force on Preventive Health Care, ${ }^{56}$ we considered the evidence for and against assessing asymptomatic children for OME. Our focus was the first 4 years of life because this is the period of most rapid language acquisition.

\section{Methods}

The "causal (analytic) pathway" approach considers evidence for an entire programme for early detection; if this is not available, evidence is considered for each step in an analytic pathway (fig 1). ${ }^{7}$ Regarding programmes for earlier detection of OME, the analytic pathway involved examining evidence for the effectiveness of screening the general population for OME in the first 4 years of life to prevent delayed language development (step 1). If such evidence was lacking, the remaining steps in the pathway were considered as follows:

- Is there a suitable tool for early detection (step 2)?

- Is treatment effective in clearing effusions (step 3)?

- Does treating OME improve language related outcomes (step 4)?

- Is there is an association between OME and delayed language development (step 5)?

The guidelines for rules of evidence established by the Canadian Task Force on Preventive Health Care were used to classify the quality of study designs in a hierarchical fashion (box 1). ${ }^{89}$ 


\section{Box 1 Canadian Task Force on Preventive Health Care: levels of evidence and grades of recommendations}

QUALITY OF PUBLISHED EVIDENCE

I Evidence from at least one properly randomised controlled clinical trial

II-1 Evidence from well designed controlled trials without randomisation

II-2 Evidence from well designed cohort or case-control analytic studies, preferably from more than one centre or research group

III-3 Evidence from comparisons between times or places with or without the intervention; dramatic results in uncontrolled experiments could also be included here

III Opinions of respected authorities, based on clinical experience, descriptive studies, or reports of expert committees

MEDLINE was searched from 1966 to July 2000 , focusing on screening (in general and in the early years), treatment (and subsequent language related outcomes), and the relation between OME and language delay. Key search terms used included otitis media with effusion (OME), middle ear effusion, developmental disabilities, learning disorders, child development, language development disorders, speech disorders, mass screening, sensitivity, and specificity. The Cochrane database of systematic reviews and controlled trials register, as well as the NHS centre for reviews and dissemination database were also searched for relevant studies and meta-analyses.

Further studies were identified from manual searching of the indexes of studies identified by electronic searchers, from indexes of review studies, and from the index of the systematic review by the New Zealand health technology assessment clearing house for health outcomes and health technology assessment (http:// nzhta.chmeds.ac.nz/screen.htm). If a metaanalysis of suitable quality was found, only relevant individual trials published after the meta-analysis were sought.

Studies were excluded for the following reasons:

- assessment of exposure that was retrospective or inadequate;

- use of samples other than the general population, for example studies that included only graduates of neonatal units, children with cleft palate, high risk children in day care, or specific ethnic groups;

- evaluation of OME after the first 4 years of life;

- findings published in abstract form or in conference proceedings only.

The evidence was systematically reviewed using the methods of the Canadian Task Force on Preventive Health Care. Two authors extracted information from and assessed the quality of the individual studies. The task force of expert clinicians/methodologists from a variety of medical specialities used a standardised evidence based method for evaluating the effectiveness of screening interventions. The full methodology is described by Woolf et al. ${ }^{8}$

\section{Results}

STEP 1: DOES SCREENING THE GENERAL POPULATION OF CHILDREN IN THE FIRST 4 YEARS OF LIFE PREVENT DELAYED LANGUAGE DEVELOPMENT?

We identified no trials assessing the entire screening process for OME (early detection and intervention), where subjects were randomised to be screened and treated if early abnormality is detected, or not screened. However, one trial assessed the impact of screening a general population of children aged 2 years and those with persistent effusions invited to participate in a randomised trial. ${ }^{110}{ }^{11}$ Owing to small numbers, the study lacked sufficient power to detect a clinically important effect.

Three other "screening" studies were excluded because audiometry was the screening tool and subjects were not randomised. ${ }^{12-14}$ Two of these studies focused on older children. ${ }^{12}{ }^{13}$ Three studies were excluded because referral rate was the outcome measure..$^{15-17}$ Given the lack of evidence for or against screening for $\mathrm{OME}$ in the general population, we then explored the remaining steps in the analytic pathway (fig 1).

STEP 2: IS THERE A SUITABLE TOOL FOR EARLY DETECTION?

Hearing tests

Not all children with OME suffer important hearing $\operatorname{loss}^{18}$ so an effective tool that directly evaluates hearing loss caused by OME would be ideal. However, manoeuvres that examine hearing deficits - such as audiograms or distraction tests-are not yet useful for early detection. The former tests are not often feasible in children less than 4 years of age and are resource intensive, ${ }^{19}$ while the latter are not sufficiently sensitive. ${ }^{20}$

\section{Tympanometry}

In presurgery populations, several studies found sensitivities and specificities for tympanometry of above $80 \% .{ }^{21-26}$ In studies involving populations with a lower prevalence of OME that use otoscopy as the gold standard, sensitivities of around $80 \%$ and specificities of more than $90 \%$ were reported. ${ }^{26}{ }^{27}$ Two studies assessed tympanometry in a community setting using pneumatic otoscopy as the gold standard. ${ }^{27}$ The sensitivities were $65 \%$ and $95 \%$, and the specificities were $65 \%$ and $80 \%$. Microtympanometry compared well with standard tympanometry. ${ }^{29-34}$ As not all children with effusions suffer hearing loss ${ }^{18}$ tympanometry is therefore a surrogate measure for hearing loss. Positive predictive values ranged from $49 \%$ to $66 \%$ for a hearing loss greater than or equal to $25 \mathrm{~dB}$ (over $0.5,1$, and $2 \mathrm{kHz}$ ) after an abnormal tympanogram in referred populations. ${ }^{183536}$ 
Acoustic reflectometry

Reported sensitivities and specificities of acoustic reflectometry varied widely. ${ }^{23} 37-48$ However, the performance of the newer reflectometers approaches that of tympanometers. ${ }^{23} 42$

\section{Pneumatic otoscopy}

A review of five studies comparing pneumatic otoscopy with fluid present at the time of surgery found a mean sensitivity of $89 \%$ and a mean specificity of $80 \% .{ }^{49}$ In one study, pneumatic otoscopy identified less than half the effusions noted on computed tomography. ${ }^{50}$ In a comparison with tympanometry in a primary care setting, where the prevalence of OME was $31 \%$, otoscopy had a sensitivity of $76 \%$ and a specificity of $87 \% .^{51}$

Decisions based on a combination of otoscopy, tympanometry, and middle ear muscle reflex measures have high sensitivities and specificities, ${ }^{52}$ but this approach is resource intensive and has not been tested for use in clinical practice. ${ }^{54}$

\section{Problems with tools for early detection}

When assessing the properties of manoeuvres used for the early detection of OME, fluid found in the middle ear at the time of surgery is often considered the gold standard, rather than hearing loss associated with OME in primary care. As the prevalence of $\mathrm{OME}$ affects positive and negative predicative values of these manoeuvres, it is important that such characteristics be examined in community samples. ${ }^{55}$ Children in presurgery samples may also differ from those considered for early detection in other important variables such as age, duration of OME, and related conditions.

Relatively low levels of agreement among potential manoeuvres for early detection have been reported. ${ }^{56}$ Interobserver reliability has also been found to be moderate..$^{57}$

These problems with candidate tools for early detection are compounded by the recurrent and fluctuating nature of OME: it is only long term OME that warrants treatment; a single measure of any type will fail to document clinically relevant chronicity. Children with positive tests would need to begin a period of observation with repeated testing.

STEP 3: IS TREATMENT EFFECTIVE IN CLEARING OME?

Mucoactive drugs

A meta-analysis concluded that patients with OME receiving oral S-carboxymethylcysteine or its lysine salt versus placebo benefited by avoiding surgical intervention 2.31 times more often $(95 \%$ confidence interval (CI), 1.28 to $4.2 ; \mathrm{p}<0.01)$, and by reverting to normal tympanograms more often (odds ratio 2.25 ( $95 \% \mathrm{CI}, 0.97$ to 5.22$) ; \mathrm{p}=0.058) .{ }^{59}$ Longer term effects such as recurrences were not reported. Studies included placebo and no treatment controls, but outcome assessors were blinded to treatment condition. In all but one of the six individual studies considered, confidence intervals for odds ratios included unity. The single study showing benefit included 19 subjects for analysis; the odds ratio favouring mucolytics was 18.92 (95\% CI, 2.03 to 177.6$)$.

\section{Antibiotics}

Williams and colleagues' meta-analysis examined the effectiveness of antibiotic prophylaxis of recurrent otitis media and found a rate difference of 0.11 favouring antibiotic treatment $(95 \%$ CI, 0.03 to 0.19$) .{ }^{60}$ Studies examining outcomes at one month following antibiotic treatment of OME had a rate difference favouring antibiotics of $0.16(95 \% \mathrm{CI}, 0.03$ to 0.29). Studies without a placebo control group showed greater antibiotic effect than placebo controlled trials. Three studies evaluated hearing. There were no significant differences in outcomes between the groups that received placebo compared with antibiotics in studies of longer term outcome of OME, that is from six weeks to 11 months after starting treatment (rate difference 0.06 (95\% CI, -0.03 to 0.14$)$ ).

Other meta-analyses also found that antibiotics promoted the resolution of OME in the short term..$^{54}$

Since these meta-analyses were done, there have been three further relevant trials confirming that antibiotics have an effect on preventing recurrent acute otitis media ${ }^{62}$ and in promoting the short term resolution of OME. ${ }^{63}{ }^{64}$ Long term effects on language were not assessed, and side effects of antibiotic treatment were reported in $44 \%$ of antibiotic treated versus $22 \%$ of control children in one study of treatment of OME. $^{63}$

Steroids

The Agency for Health Care Policy and Research (now known as the Agency for HealthCare Research and Quality) found contradictory evidence for steroid treatment alone or in combination with an antibiotic and did not recommend the use of steroids for OME. ${ }^{54}$ A previous meta-analysis found that children receiving steroids for 7 to 14 days were 3.6 times more likely than placebo controlled subjects to have both ears free of effusion at the end of treatment (95\% CI, 2.2 to 4.1$).^{65}$ However, there was significant heterogeneity of results, and the studies generally involved small samples (range 22 to 60 ). Since these metaanalyses, a trial showed benefit from adding oral steroid to antibiotic treatment after two weeks, but this advantage was no longer apparent at six weeks and six months. ${ }^{66}$

Topical (intranasal) steroid combined with an oral antibiotic was effective in clearing effusions in the short term, but by 12 weeks of treatment differences in most outcomes were no longer statistically significant. ${ }^{67}$

Surgery

A systematic review of well designed randomised controlled trials examining the effectiveness of surgical interventions for OME concluded that ventilation tubes and adenoidectomy alone or in combination were equally effective. $^{19}$ Meta-analysis was not possible because of variability across studies. On the 
basis of three studies, the authors estimated that the magnitude in reduction of hearing loss was on average $12 \mathrm{~dB}$ at 6 months and under 6 $\mathrm{dB}$ after 12 months following surgery. There was a large variation in effect between children. Myringotomy alone, tonsillectomy alone, or combinations of the two were ineffective interventions. Ventilation tube insertion was noted to lead to tympanosclerosis and slightly increased the incidence of chronic perforation and cholesteatoma. Risks of surgery included exposure to an anaesthetic, possible psychological trauma, and a slight risk of haemorrhage after adenoidectomy. Between $20 \%$ and $35 \%$ of those receiving ventilation tubes experienced ear discharge, which was persistent in $5 \%$ of cases.

Since this systematic review, ${ }^{16}$ further reports from one of the studies showed that the median duration of OME was reduced by surgery, especially by the combination of a tube and adenoidectomy ${ }^{68}{ }^{69}$ However, a recent study of adenoidectomy and adenotonsillectomy for recurrent acute otitis media showed short term and limited efficacy in preventing episodes of acute otitis media and in reducing the estimated proportion of time with effusions. ${ }^{70}$

\section{Other interventions}

Auto-inflation (including nose blowing) has limited applicability in young children. A meta-analysis found studies of autoinflation to be of variable and low quality; its use was not recommended for clinical practice. ${ }^{71}$

The role of non-steroidal anti-inflammatory drugs may be explored in larger, well designed studies. In two underpowered, placebo controlled trials, there was a non-significant trend favouring treatment with these agents. ${ }^{72} 73$

A pilot study found a non-significant trend in favour of homeopathic treatment versus usual care for OME. ${ }^{74}$

A meta-analysis of studies of antihistamines combined with decongestant treatment showed no effect on resolution of OME. ${ }^{54}$

STEP 4: DOES TREATING OME IMPROVE LANGUAGE RELATED OUTCOMES?

The studies assessing language related outcomes are summarised in table 1 .

A randomised controlled trial examined the effect of treatment on language related outcomes in children recruited to the trial at the time of their first appointment at an otolaryngology clinic. ${ }^{75}$ Bilateral effusions and hearing loss were documented prospectively for at least 3 months, after which children were randomised to receive ventilation tubes within 6 weeks, or, if required, after a period of 9 months of "watchful waiting". Nine months after randomisation, those assigned to the watchful waiting group had verbal comprehension and expressive language skills that were 3.24 months behind those in the early surgery group. Eighteen months after randomisation, $85 \%$ of the watchful waiting group had undergone tube insertion, and the groups no longer differed significantly with regard to language related outcomes.
As outlined in table 1, the remaining studies included five controlled cohort studies. The sample sizes ranged from 25 to 58 participants; the findings regarding the effect of treatment on language ability were conflicting. ${ }^{76-80}$

\section{STEP 5: IS OME ASSOCIATED WITH DELAYED}

LANGUAGE DEVELOPMENT?

Table 2 summarises the 13 groups of studies identified that considered the effect of OME on language acquisition during the first 4 years of life.

Two studies had high internal validity. Lous and Fiellau-Nikolajsen and Lous et al screened more than $90 \%$ of two separate entire birth cohorts in a Danish municipality; follow up was achieved for more than $65 \%$ of the children in both cohorts who had significant OME ${ }^{81}{ }^{82}$ In these studies, cases were carefully matched with controls. No lasting effects from OME were found. However, outcome was measured at age 8 years, by which time children who had experienced OME may have caught up with their unaffected peers. In one of the studies, follow up evaluation involved only the silent reading word test.

The remaining 11 study groups had methodological flaws that posed substantial threats to internal validity. Only three studies documented hearing loss associated with effusions. $^{83-85}$ Reports from studies of the Nijmegen cohort suffered from possible attrition bias. ${ }^{86} 87$ Although documentation of OME was comprehensive and screening occurred at regular intervals, no attempt was made to follow up all screened subjects with language related assessments. For example, Peters and colleagues did not indicate how subjects were selected for language assessment from the original sample screened for exposure to OME. ${ }^{87}$ The extent of subject overlap across studies was not clear: it appeared that some children might have been included in more than one report of outcomes. If this was the case, the studies could not be considered independent. Few significant differences in language outcomes attributable to OME were found, despite multiple comparisons.

Paradise and colleagues report follow up for a subsample of children enrolled in their ongoing study. ${ }^{85}$ Children from diverse backgrounds were enrolled by the age of 2 months and middle ear status was monitored at least monthly with hearing tests for those with ongoing OME. Children in this cohort who met inclusion criteria for a trial of treatment with ventilation tubes became ineligible. The remaining children represented a broad range of exposure to OME. They were randomly selected from the remaining cohort for evaluation of language development, speech, and sound production at 3 years of age. The percentage of variance in scores for receptive vocabulary and verbal aspects of cognition explained by time with OME in the first year of life, beyond that explained by sociodemographic variables, ranged from $1.2 \%$ to $2.9 \%$. There were no significant correlations between time with OME and scores on measures of spontaneous expressive language, the $A D C$ website

www.archdischild.com 
speech and sound production, or other measured aspects of cognition.

Similarly, the study by Friel-Patti and Finitzo achieved follow up for less than one third of subjects at age 2 years. ${ }^{88}$ Only two of 10 comparisons showed a statistically significant association between exposure to otitis media and language delay at age 2 years. A further evaluation of a non-random subsample found that the risk of delayed language development depended on average hearing levels during exposure to OME. ${ }^{89}$

The two studies by Teele and colleagues should be considered to be one study as the reports followed essentially the same children at different times. ${ }^{90} 91$ Duration of OME was calculated by extrapolation from the number of episodes of acute otitis media. Those followed up at 3 years were not randomly selected from the original cohort, and less than $10 \%$ of those initially recruited underwent language assessments at the follow up points. At 3 years of age, children with OME had lower scores on the three tests used to assess speech and language. At the 7 year follow up, the relation between time with $\mathrm{OME}$ and language was significant in two of nine comparisons.

Kinshkowy and colleagues explored the association between recurrent otitis media and language outcomes. ${ }^{92}$ As in the studies by Teele and colleagues, inferences were made about duration of effusions from documented episodes of acute otitis media. More than $80 \%$ of the participants were assessed at follow up at 2 and 3 years of age, during the period when effects of exposure might be most apparent. A multivariate analysis included social variables and otitis media history and showed that only recurrent otitis media made a statistically significant contribution to the overall developmental quotient and specifically to its language subsection at 2 years of age.

The study by Wright and colleagues ${ }^{93}$ had several methodological weaknesses. Recruitment occurred in the context of a study on vaccinations, leading to possible "volunteer bias." Follow up of the original sample fell below $50 \%$, and blinding of language assessors to otitis history was not mentioned. No measure of otitis media influenced language outcomes.

Vernon-Feagans and colleagues documented exposure meticulously, but the sample numbers were small ( $\mathrm{n}=36,46$, and 36 ), and it was not clear if their studies were independent. ${ }^{83} 8494$ The findings supported the "cumulative effects model," in that an association was only found for chronic otitis media and language outcomes among those attending day care of poorer quality.

It was not appropriate to combine the data from studies in table 2 owing to the variability in outcome, assessment of exposure, attrition, and duration of follow up.

\section{Discussion}

Although the association between OME and language development has undergone considerable investigation, few studies have directly addressed the question of early detection in the first 4 years of life. The analytic pathway approach is therefore particularly important to consider when examining the evidence for or against early detection.

We identified no randomised controlled trials examining the overall process of screening for OME in the first 4 years of life with a preventive manoeuvre for adverse language outcomes. However, one trial screened children and then randomised those with persistent effusions to be treated with ventilation tubes or not. No effect on language was identified but there was probably insufficient power to detect a clinically important difference (step 1 in the analytic pathway).

Various manoeuvres for early detection are available, but performance has not been adequately assessed in community settings, where the prevalence and severity are lower than in presurgery groups. Indeed, manoeuvres have to be evaluated against each other in this setting, where it is not possible to use the gold standard of documented hearing loss associated with the presence of middle ear fluid found at tympanocentesis (step 2 in the analytic pathway). No single reading can give an indication of chronicity, which is crucial in a condition that fluctuates and is often self limiting.

Most treatments were evaluated in populations identified through usual care. Studies of antibiotics have shown some short term benefit in clearing effusions (step 3 in the analytic pathway), but long term resolution of effusions has not been demonstrated. Antibiotics helped to reduce recurrences of acute otitis media. Evidence for benefit in the short and medium term must be considered in the context of rising bacterial resistance, side effects, and lack of evidence for long term improvement in hearing in children with OME. A meta-analysis of trials of mucolytics suggests possible short term benefit. Surgical management alone or in combination cleared fluid and improved hearing - a systematic review showed ventilation tubes and adenoidectomy were equally effective, with some evidence suggesting the combination was better than either procedure alone. Treatment effectiveness studies generally used intermediate outcomes of effectiveness, such as resolution of OME based on tympanometry. Thus it is not known whether early detection of OME with subsequent treatment using methods other than ventilation tubes prevents adverse language outcomes.

There is good evidence that treatment of OME with ventilation tubes compared with watchful waiting improves language outcomes at 9 months (step 4 in the analytic pathway). However, by 18 months, differences were no longer apparent. This was a study of management among children referred to an otolaryngology clinic and not an evaluation of additional interventions for earlier detection. Consequently, this trial does not provide evidence to support attempts at earlier detection of OME.

With regard to step 5 in the analytic pathway, in five study groups there was no association between OME and language outcomes, while 
in eight study groups a minority of analyses showed a significant association. Sociodemographic variables appeared to account for more of the variance in measures of language development than exposure to OME. There was substantial variability across study groups in measurement of exposure (severity, laterality, associated hearing loss, and persistence of OME) and in outcome, and many of the studies had major methodological weaknesses. For example, not all children with effusions suffer from significant hearing loss, a factor that is often considered as the causal link between $\mathrm{OME}$ and language delay; a wide range of language and developmental outcomes was used, and the clinical importance of results obtained with these measures was not clear; and interpretation of significant findings was difficult because of the broad array of language tests used without accompanying information about the clinical importance of change scores. In addition, there was a high rate of intervention for OME in the studies, which may have affected the outcomes.

\section{INTERPRETATION}

On the basis of these findings we conclude that there is insufficient evidence to make recommendations for or against the use of tympanometry, microtympanometry, acoustic reflectometry, and pneumatic otoscopy for the earlier detection of OME in the general population of children up to 4 years of age. There is insufficient evidence to recommend early detection of OME in children in the first 4 years of life to prevent delayed language development.

These conclusions were also reached by the Canadian Task Force on Preventive Health Care. The US Agency for Health Care and Policy Research expert panel did not make a recommendation about early detection of OME. ${ }^{54}$ The New Zealand health technology assessment clearing house for health outcomes and health technology assessment (http:// nzhta.chmeds.ac.nz/screen.htm) stated that it was not possible to conclude whether or not screening programmes for OME in preschool children are an effective health strategy. The report by Haggard and Hughes for the United Kingdom Department of Health recommended against extending preschool screening for OME. ${ }^{95}$

\section{FUTURE RESEARCH}

Tools for early detection should be evaluated in settings of low prevalence. Future studies on the identification, effects, and treatment of OME should document hearing loss associated with OME prospectively over time. Unilateral $\mathrm{OME}$ is unlikely to result in hearing loss warranting intervention, and laterality should be reported. Outcomes should include behavioural assessments (for example, measures of concentration) as well as language assessments. The reliability and validity of these outcome measures should be described, and clinically important differences specified. Regarding screening the general population for OME, a randomised controlled trial which allocates children at the level of exposure to strategies for early detection would be necessary to determine the effectiveness of the overall screening process (early detection and subsequent management) in preventing language delay. However, such a resource intensive trial is not justified without evidence that OME causes clinically important deficits in language and other developmental outcomes that can be reduced with treatment.

We are grateful to The Canadian Task Force on Preventive Health Care for their contributions to a technical report on this topic. Also, the following peer reviewers for the Task Force made helpful comments on drafts of the technical report: Drs Alfred O Berg, Department of Family Medicine, University of Washington School of Medicine, Seattle, Washington, USA and Chair, US Preventive Services Task Force; Larry Culpepper, Department of Family Medicine, Boston University Medical Center, Boston, Massachusetts, USA; Mark Haggard, MRC Institute of Hearing Research Nottingham, United Kingdom, sity, Denmark. The views expressed in this paper are those of the sity, Denmark. The views expressed in this paper are those of the authors and the task force and do not necessarily reflect the positions of the reviewers. CCB was supported by an NHS Wocial Care clinical research fellowship. HLM was supported by Social Care clinical research fellowship. HLM was supported
a faculty scholar award from the WT Grant Foundation.

1 Zielhuis GA, Rach GH, van den Broek P. Screening for otitis media with effusion in preschool children. Lancet 1989;i:311-13.

2 Fiellau-Nikolajsen M. Epidemiology of secretary otitis media: a descriptive study. Ann Otol Rhinol Laryngol 1983; 92:172-7.

3 Roberts JE, Wallace IF. Language and otitis media. In: Roberts JE, Wallace IF, Henderson FW, eds. Otitis media in young children: medical, developmental, and educational considyoung children: medical, developmental, and educational consid

4 Lous J. Secretary otitis media in schoolchildren: is screening for secretary otitis media advisable? Danish Med Bull 1995: for secretary

5 Woolf SH, Battista RN, Anderson GM, et al. Assessing the clinical effectiveness of preventive maneuvers: analytic principles and systematic methods in reviewing evidence and developing practice recommendations. $\mathcal{F}$ Clin Epidemiol 990;43:891-905.

6 Canadian Task Force on the Periodic Health Examination. The periodic health examination: 1989 update part 3, preschool examination for developmental, visual and hearing problems. Can Med Assoc f 1989;141:1136-40.

7 Battista R, Fletcher S. Making recommendations on preventive practices: methodological issues. In: Battista $\mathrm{R}$, Lawrence $\mathrm{R}$, eds. Implementing preventive services. New York: Oxford University Press, 1988:53-67.

8 Woolf S, Battista RN, Geoffrey M. Assessing the clinical effectiveness of preventive maneuvers: analytic principles and systematic methods in reviewing evidence and developing clinical practice recommendations. I Clin Epidemiol 1990;43:891-905.

9 Canadian Task Force on the Periodic Health Examination. The periodic health examination. Can Med Assoc $f$ 1979;121:1193-254

10 Rach GH, Zielhuis GA, van Baarle PW, et al. The effect of treatment with ventilating tubes on language development in preschool children with otitis media with effusion. Clin Otolaryngol 1991;16:128-32.

11 Schilder AG, Van Manen JG, Zielhuis GA, et al. Long term effects of otitis media with effusion on language, reading and spelling. Clin Otolaryngol 1993;18:234-41.

12 Feldman W, Milner RA, Sackett B, et al. Effects of preschool screening for vision and hearing on prevalence of vision and hearing problems 6-12 months later. Lancet 1980;ii:1014 16.

13 Augustsson I, Nilson C, Engstrand I. The preventive value of audiometric screening of preschool and young schoolof audiometric screening of preschool and young school
children. Int 7 Pediatr Otorhinolaryngol 1990;20:51-62.

14 O'Mara LM, Isaacs S, Chambers LW. Follow-up of participants in a preschool hearing screening program in child pants in a preschool hearing screening program

15 Crampton P, Bandaranayake D. Evaluation of an otitis media with effusion screening pilot program. NZ Med $\mathcal{F}$ 1996;109:384-6.

16 Lucker J. Application of pass fail criteria to middle ear screening results. ASHA 1990;22:839-40.

17 Roush J, Tait CA. Pure-tone and acoustic immittance screening of pre-school aged children: an examination of referral criteria. Ear Hear 1985;6:245-50.

18 MRC Multi-Centre Otitis Media Study Group. Sensitivity, specificity and predictive value of tympanometry in predicting a hearing impairment in otitis media with effusion. Clin Otolaryngol 1999;24:284-300.

19 Freemantle N, Sheldon TA, Song F, et al. The treatment of persistent glue ear in children: Are surgical interventions effective in combating disability from glue ear? Effective Health Care 1992;4:1-16.

20 Davis AC, Wood S. The epidemiology of childhood hearing impairment: factors relevant to planning of services. $\mathrm{Br} \mathcal{F}$ Audiol 1992;26:77-90. 
21 Cooper JC, Hearne EM, Gates GA. Normal tympanometric shape, Ear Hear 1982;3:241-5.

22 Finitzo T, Friel-Patti S, Chinn K, Brown O. Tympanometry and otoscopy prior to myringotomy: issues in diagnosis of and otoscopy prior to myringotomy: issues in diagnosis of

23 Barnett ED, Klein JO, Hawkins KA, et al. Comparison of spectral gradient acoustic reflectometry and other diagnostic techniques for detection of middle ear effusion in children with middle ear disease. Pediatr Infect Dis f 1998; 17:556-9.

24 Mills RP. Persistent middle ear effusions in children with recurre

25 Fiellau-Nikolajsen M. Tympanometry and middle ear effusion: a cohort study in three year old children. Int $\mathcal{f}$ Pediatr Otorhinolaryngol 1980;2:39-49.

26 Nozza RJ, Bluestone CD, Kardatzke D, et al. Towards the validation of aural acoustic immittance measures for diagnosis of middle ear effusion in children. Ear Hear 1992;13: 442-53.

27 Roush J, Drake A, Sexton JE. Identification of middle ear dysfunction in young children: a comparison of tympano1992;13:63-9.

28 Page AR, Kramer S, Novak J, et al. Tympanometric screening in elementary school children. Audiology 1995;34:6-12.

29 Fields MJ, Allison RS, Corwin P, et al. Microtympanometry, microscopy and tympanometry in evaluating middle ear

Vaughn-Jones R, Mills RP. The Welch Allyn audioscope and microtymp: their accuracy and that of pneumatic otoscopy, tympanometry and pure tone audiometry as predictors of otitis media with effusion. F Laryngol Otol 1992;106:600-2.

31 van Balen FAM. Validation of a portable tympanometer for use in primary care. Int $\mathcal{F}$ Pediatr Otorhinolaryngol 1994;29: 219-25.

32 Koivunen P, Alho O-P, Uhari M, et al. Minitympanometry in detecting middle ear fluid. $\mathcal{F}$ Pediatr 1997;131:419-42.

33 De Melker RA. Diagostic value of microtympanometry in primary care. BMF 1992;304:96-8.

34 Wazen JJ, Ferraro JA, Hughes R. Clinical evaluation of a portable, cordless, hand-held middle ear analyzer. Otolaryngol Head Neck Surg 1988;99:348-50.

35 Dempster JH, Mackenzie K. Tympanometry in the detection of hearing impairments associated with otitis media with effusion. Clin Otolaryngol 1991;16:157-9.

36 Kzanas SG, Maw R. Tympanometry, stapedius reflex and hearing impairment in children with otitis media with effusion. Acta Otolaryngol (Stockh) 1994;114:410-14.

37 Schwartz DM, Schwartz RH. Validity of acoustic reflectometry in detecting middle ear effusion. Pediatrics 1987;79: $739-42$.

38 Babonis TR, Weir MR, Kelly PC. Impedance tympanometry and acoustic reflectometry at myringotomy. Pediatrics 1991:87:475-80.

39 Oyiborohoro JMA, Olaniyan SO, Newman CW, et al. Efficacy of acoustic otoscope in detecting middle ear effusion in children. Laryngoscope 1987;97:495-8.

40 Douniadakis DE, Nikolopoulos TP, Tsakanikos MD, et al. Evaluation of acoustic reflectometry in detecting otitis media in children. Br f Audiol 1993;27:409-14.

41 Combs JT. Predictive value of the angle of acoustic reflectometry. Pediatr Infect Dis f 1991;10:214-16.

42 Block SL, Mandel E, Mclinn S, et al. Spectral gradient acoustic reflectometry for the detection of middle ear effusion by pediatricians and parents. Pediatr Infect Dis $\mathcal{F} 1998$; 17:560-4.

43 Pellett FS, Cox LC, MacDonald CB. Use of acoustic reflectometry in the detection of middle ear effusion. $7 \mathrm{Am} \mathrm{Acad}$ Audiol 1997;8:181-7.

44 Silman S, Silverman CA, Arick DS. Acoustic-immittance screening for detection of middle-ear effusions in children. screening for detection of middle
7 Am Acad Audiol 1992;3:262-8.

45 Kemaloglu YK, Sever T, Beder L, et al. Predictive value of acoustic reflectometry (angle and reflectivity) and tympanometry. Int $\mathcal{F}$ Pediatr Otorhinol 1999;48:137-42.

46 Buhrer K, Wall LG, Schuster L. The acoustic reflectometer as a screening device: a comparison. Ear Hear 1985;6:30714.

47 Macknin ML, Skibinski C, Beck G, et al. Acoustic reflectometry detection of middle ear effusion. Pediatr Infect Dis $\mathcal{F} 1987 ; 6: 866-8$.

48 Avery CA, Gates GA, Prihoda TJ. Efficacy of acoustic reflectometry in detecting middle ear effusion. Ann Otol Rhinol Laryngol 1986;95:472-6.

49 Preston K. Pneumatic otoscopy: a review of the literature. Issues in Comprehensive Pediatric Nursing 1998;21:117-28.

50 Takahashi H, Honjo I, Hasebe S, et al. The diagnostic and prognostic value of eardrum mobility in OME. Eur Arch Otol Rhinol Laryngol 1999;256:189-91.

51 Reves R, Budgett R, Miller D, et al. Study of middle ear disease using tympanometry in general practice. $B M f$ 1985;290:1953-6.

52 Bluestone CD, Cantekin EI. Design factors in the characterization and identification of otitis media and certain related conditions. Ann Otol Rhinol Laryngol 1979;5: $13-18$.

53 Cantekin EI, Bluestone CD, Fria TJ, et al. Identification of otitis media with effusion in children. Ann Otol Rhinol Laryngol 1980;89:s190-5.

54 Stool SE, Berg AO, Berman S, et al. Otitis media with effusion in young children. Clinical practice guideline. Number 12. Rockville, Maryland: Agency for Health Care Policy and Research, Public Health Services, US Department of Health and Human Services, 1994.
55 Fletcher RH, Fletcher SW, Wagner EH. Clinical epidemiology: the essentials. Baltimore, Maryland: Williams and Wilkins, 1996.

56 McCandless GA, Thomas GK. Impedance audiometry as a screening procedure for middle ear disease. Trans Am Ophthalmol Otol 1974;78:98-102.

7 Labrecque M, Dostaler LP, Dumont H, et al. Reproductibilité interobservateur d'un tympanomètre portatif, le Micro Tymp. Can Med Assoc f 1993;148:559-64.

58 van Balen FAM, Aarts AM, De Melker RA. Tympanometry by general practitioners: reliable? Int $\mathcal{f}$ Pediatr Otorhinolaryngol 1999;48:117-23.

59 Pignataro O, Pignataro LD, Gallus G, et al. Otitis media with effusion and S-carboxymethylcysteine and/or its lysine salt: a critical overview. Int $\mathcal{F}$ Pediatr Otorhinolaryngol 1996; 35:231-41.

60 Williams RL, Chalmers TC, Stange KC, et al. Use of antibiotics in preventing recurrent acute otitis media and in otics in preventing recurrent acute otitis media and in
treating otitis media with effusion. $\mathcal{F} M A$ 1993;270:134451.

61 Rosenfeld RM, Post JC. Meta-analysis of antibiotics for the reatment of otitis media with effusion. Otolaryngol Head Neck Surg 1992;106:378-86

62 Mandel EM, Casselbrant ML, Rockette HE, et al. Efficacy of antimicrobial prophylaxis for recurrent middle ear effusion. Pediatr Infect Dis 1996;15:1074-82.

63 van Balen FAM, De Melker RA, Touw-Otten FWMM. Double-blind randomised trial of co-amoxicalv versus placebo for persistent otitis media with effusion in general practice. Lancet 1996;348:713-16.

64 Marchisio P, Principi N, Passali D, et al. Epidemiology and treatment of otitis media with effusion in children in their first year of primary school. Acta Otolaryngol (Stockh) 1998;118:557-62.

65 Rosenfeld RM, Mandel EM, Bluestone CD. Systemic teroids for otitis media with effusion in children. Arch Otolaryngol Head Neck Surg 1991;117:984-9.

66 Hemlin C, Carenfelt C, Papatziamos G. Single dose of betamethasone in combined medical treatment of secretory otitis media. Ann Otol Rhinol Laryngol 1997;106:359-63.

67 Tracy JM, Demain JG, Hoffman KM, et al. Intranasal beclomethasone as an adjunct to treatment of chronic middle ear effusion. Ann Allergy Asthma Immunol 1998;80:198206.

68 Maw R, Bawden R. Spontaneous resolution of severe chronic glue ear in children and the effect of adenoidectomy, tonsillectomy, and insertion of ventilation tubes (grommets). BMF 1993;306:756-60.

69 Maw AR, Bawden R. The long term outcome of secretary otitis media in children and the effects of surgical treatment: a ten year study. Acta Otorhinolaryngol Belg 1994;48:317-24.

70 Paradise JL, Bluestone CD, Colborn DK, et al. Adenoidectomy and adenotonsillectomy for recurrent acute otitis tomy and adenotonsillectomy for
media. $7 A M A$ 1999;282:945-53.

71 Reidpath DD, Glasziou PP, Del Mar CB. Systematic review of autoinflation for treatment of glue ear in children. BMF 999;318:1177-8

2 Varsano IB, Volovitz BM, Grossman JE. Effect of naproxen, a prostaglandin inhibitor, on acute otitis media and persistence of middle ear effusion in children. Ann Otol Rhinol Laryngol 1989;98:389-92.

73 Abramovich S, O'Grady J, Fuller A. Naproxen in otitis media with effusion. F Laryngol Otol 1986;100:263-6.

74 Harrison H, Fixsen A, Vickers A. A randomized comparison of homeopathic and standard care for the treatment of glue ear in children. Complementary Ther Med 1999;7:132-5.

75 Maw R, Wilks J, Harvey I, et al. Early surgery compared with watchful waiting for glue ear and effect on language development in preschool children: a randomised trial. Lancet $1999 \cdot 353 \cdot 360-3$

76 Watanabe H, Shin T, Fukaura J, et al. Total actual speaking me in infants and children with otitis media with effusion. int $\mathcal{F}$ Pediatr Otorhinolaryngol 1985;10:171-80.

77 Paden EP, Novak MA, Beiter AL. Predictors of phonologic inadequacy in young children prone to otitis media. $\mathcal{F}$ Speech Hearing Dis 1987;52:232-42.

78 Manders E, Tyberghein J. The effects of ventilation tube placement on hearing, speech, language, cognition and behaviour. Acta Otorhinolaryngol Belg 1993;47:27-32.

79 Orlin MN, Effgen SK, Handler SD. Effects of otitis media with effusion on gross motor ability in preschool-aged
children: preliminary findings. Pediatrics 1997;99:334-7.

80 Schilder AGM, Hak E, Straatman H, et al. Long-term effects of ventilation tubes for persistent otitis media with effusion in children. Clin Otolaryngol 1997;22:423-9.

81 Lous J, Fiellau-Nikolajsen M. A 5-year prospective casecontrol study of the influence of early otitis media with ffusion on reading achievement. Int $\mathcal{f}$ Pediatr Otorhinolaryngol 1984;8:19-30.

82 Lous J, Fiellau-Nikolajsen M, Jeppesen AL. Secretary otitis media and language development: a six-year follow-up study with case control. Int f Pediatr Otorhinolaryngol 1988; 15:185-203

83 Vernon-Feagans L, Emanuel DC, Blood I. The effect of otitis media and quality of day care on children's language development. F Appl Dev Psychol 1997;18:395-409.

84 Vernon-Feagans L, Manlove EE, Volling BL. Otitis media and the social behaviour of day-care-attending children. Child Dev 1996;67:1528-39.

85 Paradise JL, Dollaghan CA, Campbell TF, et al. Language, speech sound production, and cognition in three-year-old children in relation to otitis media with effusion in their first three years of life. Pediatrics 2000;105:1119-30. 
86 Grievink EH, Peters SAF, van Bon WHJ, et al. The effect of early bilateral otitis media with effusion on language ability: A prospective cohort study. I Speech Hearing Res 1993;36: 1004-12

87 Peters SAF, Grievink EH, van Bon WHJ, et al. The effects of early bilateral otitis media with effusion on educational attainment: a prospective cohort study. F Learn Disabil 1994;27:111-21.

88 Friel-Patti S, Finitzo T. Language learning in a prospective study of otitis media with effusion in the first two years of life. F Speech Hearing Res 1990;33:188-94.

89 Shriberg LD, Friel-Patti S, Flipsen P, et al. Otitis media, fluctuant hearing loss, and speech-language outcomes: a preliminary structural equation model. 7 Speech Language Hear Res 2000;43:100-20.

90 Teele DW, Klein JO, Rosner BA, for the Greater Boston Otitis Media Study Group. Otitis media with effusion during the first three years of life and development of speech and language Pediatrics 1984:74:282-7.

1 Teele DW, Klein JO, Chase C, et al. Otitis media in infancy and intellectual ability, school achievement, speech, and language at age 7 years. F Infect Dis 1990; 162:685-94.

92 Knishkowy B, Palti H, Adler B, et al. Effect of otitis media on development: a community-based study. Early Hum Dev 1991;26:101-11.

93 Wright PF, Sell SH, McConnell KB, et al. Impact of recurrent otitis media on middle ear function, hearing and language. F Pediatr 1988;113:581-7.

94 Feagans LV, Kipp E, Blood I. The effect of otitis media on the attention skills of day-care-attending toddlers. Dev Psychol 1994;30:701-8.

95 Haggard M, Hughes E. Screening children's hearing: a review of the literature and the implications for otitis media. London: HMSO, 1991.

\section{Glue ear, grommets, and adenoids}

In the USA in 1996 about 280000 children under the age of 3 years had tympanostomy tubes inserted but there is still debate about the effects of these procedures. Two papers in the New England fournal of Medicine have addressed the timing of tube insertion and the effect of removing the adenoids at the same time.

In Pittsburgh (Jack L Paradise and colleagues. New England fournal of Medicine 2001;344:1179-87) 6350 babies were studied from the age of 2-61 days. They had at least monthly pneumatic otoscopy and tympanometry up to the age of 3 years. Four hundred and twenty nine children developed persistent (90 days if bilateral, 135 days if unilateral) middle ear effusion and were randomised to either early (as soon as possible) tympanostomy tube insertion or delayed insertion (dependent on persistence of effusion up to 9 months later). By the age of 3 years the rate of tympanostomy tube insertion was $82 \%$ (early group) $v 34 \%$ (delayed group) but there were no significant differences between the two groups on tests of speech, language, cognition, and psychosocial development. These authors conclude, from these and other data, that tympanostomy tube insertion in children of this age group and with middle ear effusions of this duration produces no evident benefit by the age of 3 years (though it is possible that benefit could become apparent on testing the children when they are older). Children with more severe hearing loss or more severe ear disease might benefit from early tympanostomy.

In Toronto (Peter C Coyte and colleagues. Ibid: 1188-95) a retrospective study included over 37000 children who had tympanostomy tubes inserted between 1995 and 1997. They found that children who had had concomitant adenoidectomy (or adenotonsillectomy) were about half as likely to need reinsertion of tympanostomy tubes or to need readmission for "conditions related to otitis media". Adenoidectomy most benefited children aged 3 years or over.

An editorial (Ibid: 1241-2) calls for longer term follow up of the children in the first of these studies and points to difficulties in assessing the clinical implications of the second.

When should tympanostomy tubes be inserted? What are the benefits to be expected? What harm might it cause? Should adenoidectomy be performed at the same time? The debate will continue.

ARCHIVIST 